\title{
Group consensus and judgmental accuracy: Extension of the Asch effect'
}

JACK M. HICKS, WAKE FOREST COLLEGE
RICHARD A. MONTY, U. S. ARMY HUMAN ENGINEERING LABORATORIES THOMAS I. MYERS, NAVY MEDICAL RESEARCH INSTITUTE
This study demonstrated the generality of the Asch group influence effect to (1) a new task employing auditory rather than visual stimuli, (2) a situation in which the bogus group was not physically present, and (3) a subject population of II. S. Army enlisted personnel.

The purpose of this study was to determine if Asch's (1951) group influence effect could be generalized to a new stimulus class, judgmental situation, and $S$ population. Specifically, Asch (a) required Ss to make visual comparisons of the lengths of sets of lines presented simultaneously, (b) put $\mathrm{S}$ in face-to-face contact with a group of bogus Ss, and (c) employed a collegiate population. By contrast the present experiment (a) required Ss to make comparisons of sets of auditory signals separated temporally, (b) placed $\mathrm{S}$ in isolation using pre-recorded tapes to implement exposure to group consensus (a technique similar to that used by Blake \& Brehm (1954) in their elaboration of the Sherif (1935) autokinetic effect), and (c) utilized military personnel as Ss.

Method

Ss were 158 male enlisted personnel of the U.S. Army stationed at Fort Ord, California. All had taken the Army Classification Battery and received a minimum General-Technical subtest score of 110. Thirty-eight Ss served in the first experiment and 120 ss served in a later replication.

Ss task was to listen to a sequence of $900 \mathrm{cps}$ tones, resembling Morse Code, presented at a rate of 5.3 tones per sec. (called the "Standard Series") and to judge which of the three following sequences or "Comparison Series" had the same number of tones as the standard series. A set of six such problems (equated for difficulty) was constructed, which varied with respect to the number of tones ( 4 to 20 ) in the standard series.

In the morning, all Ss were administered a 12 trial pretest designed to familiarize the Ss with the task and to obtain scores of relevant judgmental ability. The 12 trials consisted of two repetitions of the six problems, randomly intermixed, and with the three comparison series in each trial reordered. Ss were matched in pairs on the basis of numbers of pretest errors, defined as the choice of an incorrect comparison series, and divided into a "Group Influence" group and a "No Influence" group. All Ss who committed more than four errors on the pretest or for whom no matches were available were eliminated from the experiment. Thirty Ss were thus excluded from an original population of 188. That afternoon both groups were administered an
18 trial experimental test consisting of three repetitions of the six problems newly randomized and with the order of presentation of the three associated comparison series again rearranged. The "No Influence" Ss were merely told that they would receive more problems of the same type they had received earlier in the day. The "Group Influence"' Ss were given identical information, but in addition were told that they were one of five men simultaneously listening to the problems in separate rooms. They were further told that they would be able to hear one another's judgments over the intercom and that they should make their judgments when their number $(1,2,3,4$ or 5 ) was called. The true $S$ was always assigned the number 4 . One of the three intermingled sets of six problems was treated as the "critical item" set in which the "bogus group" was unanimous in making the same incorrect judgment. None of these items appeared in the first sixpresentations. The group was unanimously correct on another set of six problems, and there were one or more dissenters on the remaining six problems.

All instructions, problems and bogus group judgments were pre-recorded and presented over an intercom. The true Ss made their judgments over a microphone. This basic group influence technique, though not directly studied, has since been adapted by Wheeler, Smith, \& Murphy (1964) primarily to create experimental deception.

\section{Results}

Ss were scored in terms of the number of errors on the pretest and the number of "conformity errors" on the critical problems of the experimental test. A conformity error was defined as an incorrect response that was in agreement with the bogus group consensus (or in the case of the "No Influence" group, the corresponding response). Ss in each group were then categorized as having made (a) fewer experimental test conformity errors than pretest errors or (b) the same number or more conformity errors than pretest errors. The frequency breakdown for the "Group Influence" "and "No Influence" conditions for both the firstexperiment and the replication is shown in Table 1.

A chi square analysis based upon data from the first experiment indicated that those Ss who had been exposed to the potential influence of the bogus group consensus made significantly more errors on the "critical items" (i.e., problems for which the consensus of the bogus group was wrong) relative to errors on the pretest than did Ss who performed the task without hearing the consensus of the bogus group $\left(X^{2}=5.73, d f=1, p<.02\right)$. A 
Table 1. Comparative Frequencies of Conformity to Pretest Errors for "Group Influence" and "No Influence" Conditions

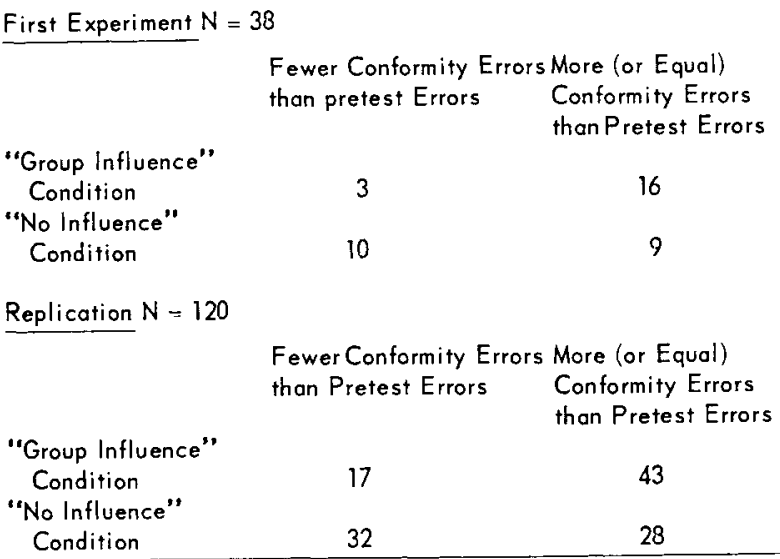

similar analysis on the replication data revealed the same effect $\left(X^{2}=7.76, \mathrm{df}=1, \mathrm{p}<.01\right)$.

\section{Discussion}

The data clearly indicate that Ss who were led to believe that four other persons were taking the test with them, were significantly influenced by the erroneous problem answers given by the bogus group. In that postexperimental interviews yielded negligible evidence that Ss exposed to the "Group Influence" condition suspected a tape recording rather than true group judgments, it seems reasonable to conclude that the generality of the Asch phenomenon in accordance with the objectives of the investigation has been demonstrated. Thus, the Asch effect would seem to be strengthened as a general law of social behavior.

Finally, the study indicates that the technique employed can be effectively used to economize and simplify creation of a group atmosphere in a manner that makes it unnecessary to hire and train bogus group collaborators. Increased control over test conditions is thus afforded. This technique would seem to have particular utility in situations in which physical presence of a bogus group is not feasible (e.g., social isolation studies, or perhaps small institutional settings where it would be difficult to obtain collaborators who were unacquainted with the naive $\mathrm{Ss})$.

\section{References}

Asch, S. E. Effects of group pressure upon the modification and distortion of judgment. In H. Guetzkow (Ed.), Groups, leadership, and men. Pittsburgh: Carnegie Press, 1951.

Blake, R. B., \& Brehm, J. W. The use of tape recording to simulate a group atmosphere. J. abnorm. soc. Psychol., 1954, 49, 311-313. Sherif, M. A study of some social factors in perception. Arch. Psychol., 1935, 27, No. 187.

Wheeler, L., Smith, S., \& Murphy, D. B. Behavioral contagion. Psychol. Rep., 1964, 15, 159-173.

\section{Note}

1. Research conducted under the auspices of the Human Resources Research office of the George Washington University under contract with the U. S. Army. The authors are grateful to Donald B. Murphy and Edward J. Kandel for their assistance in this research. The opinions and conclusions contained herein are those of the authors and are not to be construed as representing those of The George Washington University or the Department of the Army. 